\title{
Characteristics and small-scale variability of GPR signals and their relation to snow accumulation in Greenland's percolation zone
}

\author{
Thorben DUNSE, ${ }^{1,2}$ Olaf EISEN, ${ }^{1,3}$ Veit HELM, ${ }^{1}$ Wolfgang RACK, ${ }^{1,4}$ \\ Daniel STEINHAGE, ${ }^{1}$ Victoria PARRY ${ }^{5}$
${ }^{1}$ Alfred Wegener Institute for Polar and Marine Research, Am Allen Hafen 26, D-27568 Bremerhaven, Germany
${ }^{2}$ Department of Geosciences, University of Oslo, Box 1047, Blindern, NO-0316 Oslo, Norway E-mail: thorben.dunse@geo.uio.no
${ }^{3}$ Versuchsanstalt für Wasserbau, Hydrologie und Glaziologie, ETH-Zürich, CH-8092 Zürich, Switzerland
${ }^{4}$ Gateway Antarctica, University of Canterbury, Private Bag 4800, Christchurch, New Zealand
${ }^{5}$ School of GeoSciences, University of Edinburgh, Drummond Street, Edinburgh EH8 9XP, UK

\begin{abstract}
We investigate snowpack properties at a site in west-central Greenland with groundpenetrating radar (GPR), supplemented by stratigraphic records from snow pits and shallow firn cores. GPR data were collected at a validation test site for CryoSat (T05 on the Expéditions Glaciologiques Internationales au Groenland (EGIG) line) over a $100 \mathrm{~m} \times 100 \mathrm{~m}$ grid and along $\mathbf{1} \mathbf{~ k m}$ sections at frequencies of 500 and $800 \mathrm{MHz}$. Several internal reflection horizons (IRHs) down to a depth of $10 \mathrm{~m}$ were tracked. IRHs are usually related to ice-layer clusters in vertically bounded sequences that obtain their initial characteristics near the surface during the melt season. Warm conditions in the following melt season can change these characteristics by percolating meltwater. In cold conditions, smaller melt volumes at the surface can lead to faint IRHs. The absence of simple mechanisms for internal layer origin emphasizes the need for independent dating to reliably interpret remotely sensed radar data. Our GPR-derived depth of the 2003 summer surface of $1.48 \mathrm{~m}$ (measured in 2004) is confirmed by snow-pit observations. The distribution of IRH depths on a $\mathbf{1} \mathbf{~ k m}$ scale reveals a gradient of increasing accumulation to the northeast of about $5 \mathrm{~cm}$ w.e. $\mathrm{km}^{-1}$. We find that point measurements of accumulation in this area are representative only over several hundred metres, with uncertainties of about $15 \%$ of the spatial mean.
\end{abstract}

\section{INTRODUCTION}

The Greenland ice sheet is rapidly responding to changing climatic conditions. Recent analyses indicate that the amount of surface melt has been increasing during the last decade (Fettweis and others, 2007). Its mass-balance characteristics are therefore the focus of investigations by various methods using satellite and airborne platforms (e.g. Shepherd and Wingham, 2007). One standard method to determine mass changes is provided by altimetry. Surface elevation measurements are acquired at several different times to yield ice volume changes, which are converted to mass changes (D.J. Wingham and others, http://esamultimedia.esa.int/docs/ Cryosat/CVC_14Nov01.pdf). Using airborne laser altimetry acquired in 1994 and 1999, Krabill and others (2000) showed that the Greenland ice sheet is thinning at lower elevations and is generally in balance above an elevation of $2000 \mathrm{~m}$. They found an overall mass loss for the last decade of the 20th century. In contrast, Zwally and others (2005) postulated a small overall mass gain for the period 19922002 derived from satellite radar altimetry. They observed ice-sheet growth in interior areas which compensates for the thinning at the margins.

Accumulation maps of Greenland inferred by snow-pit and shallow-firn-core analysis have reported uncertainties in accumulation rates as high as $24 \%$ (Bales and others, 2001). To overcome these problems and obtain reliable ground truth for interpretation of satellite data, several validation campaigns have been carried out on the Greenland ice sheet for the European Space Agency's upcoming CryoSat2 mission.
Validation objectives focus on the relation of elevation changes to variations in accumulation and the densification process, major issues for conversion of observed volume changes to mass changes. Spatial extrapolation of pointbased results can be evaluated and significantly improved by continuous profiles of snow and firn layering using groundpenetrating radar (GPR).

Within the CryoSat pre-validation study area using the Airborne SAR Interferometric Radar Altimeter System (ASIRAS; Helm and others, 2007), we made simultaneous GPR measurements in the percolation zone together with stratigraphic studies to investigate distribution of accumulation and physical properties of snow. The survey area (Fig. 1) was located at an altitude of $1940 \mathrm{~m}$ at point T05 $\left(69.87^{\circ} \mathrm{N}\right.$, $47.33^{\circ} \mathrm{W}$ ) on the Expéditions Glaciologiques Internationales au Groenland (EGIG) line, where geodetic and glaciological investigations have been repeatedly performed since 1956 (Hofmann, 1986).

The validation of CryoSat is of great importance because of the complex process of snow metamorphosis, particularly in the percolation zone. Pfeffer and Humphrey (1996, 1998) showed that the frequency of ice-layer occurrence in polar and subpolar firn is not only dependent on the amount of surface-generated meltwater during a particular summer season. They point out the importance of the initial snowpack conditions at the onset of melt, such as snow temperature or its 'cold content', as well as the presence of stratigraphic interfaces including buried wind or radiation crusts (Male, 1980). The cold content describes the energy which is needed to heat a unit volume of snow up to melting point. 

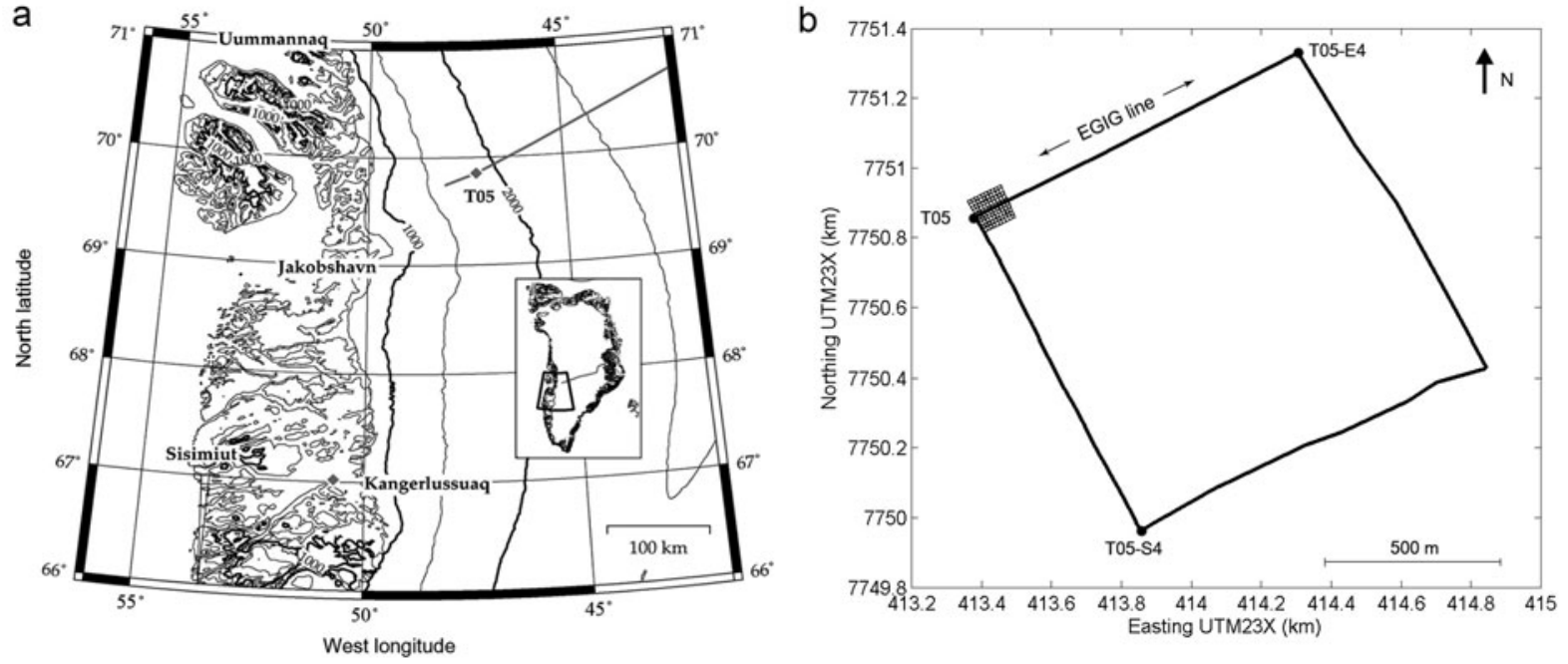

Fig. 1. (a) Map of the survey area around point T05 in the west-central region of the Greenland ice sheet. The line across the ice sheet indicates the position of the EGIG line. (b) Location of radar profiles near T05, forming a $100 \mathrm{~m} \times 100 \mathrm{~m}$ grid with $10 \mathrm{~m}$ spacing and a $1 \mathrm{~km} \times 1 \mathrm{~km}$ square.

If the initial snow temperature is low, and the snow density is moderate or high, the resulting high cold content limits the infiltration of meltwater, and typical ice layers may form and concentrate in a zone just below the summer surface. The larger, deeper fraction of the winter snowpack is left unaffected. In snowpack of low cold content, severe percolation will lead to extensive ice-layer formation and is likely to affect a greater fraction of the winter accumulation. In the case of high initial snow temperatures and warm summers, extensive breakthrough and limited ice-layer formation results in isolated ice lenses. The majority of refreezing meltwater is expected in the lowermost fraction of the winter accumulation, eventually accreted as thick ice on top of the previous summer surface (Pfeffer and Humphrey, 1996).

Summer surface melting and internal refreezing of percolating meltwater cause significant densification of the snowpack and large seasonal variability of radar backscatter properties at T05 (Parry and others, 2007). Solid ice structures in the snowpack from the previous winter, stemming from meltwater penetration, produce strong dielectric inhomogeneities which cause rapid signal attenuation with depth (Kanagaratnam and others, 2004). Earlier GPR studies, along with physical snow properties measurements, were undertaken in the vicinity of T05 at Crawford Point (Jezek and others, 1994) and near Dye-2 (Zabel and others, 1995) at centre frequencies in the C-band $(5.3 \mathrm{GHz})$ and $\mathrm{Ku}$-band $(13.5 \mathrm{GHz})$ with bandwidths of $700 \mathrm{MHz}$ and $2 \mathrm{GHz}$, respectively.

Intense radar reflections originated from a volume immediately below the previous summer surface. They were associated with solid ice structures in an upper fraction of the annual accumulation. While Zabel and others (1995) could track these features over long distances, more recent GPR measurements at T05 (Scott and others, 2006), applying the same frequency range, did not produce continuous internal reflection horizons (IRHs). Simultaneous observations of the snow and firn stratigraphy showed little evidence of lateral continuous ice layers, even at short length scales of $1 \mathrm{~m}$. Prior to the onset of surface melt, ASIRAS proved capable of detecting a strong volume signal which could be traced continuously. The volume signal originated from solid ice structures below the undisturbed winter accumulation (Helm and others, 2007), enabling the mapping of winter accumulation along the flight-line.

In this study, we present GPR data collected at the same location, but at significantly lower frequencies in the P-band (500 and $800 \mathrm{MHz}$ ). We investigate the origin of continuous IRHs and interpret the formation process of related features in the snowpack. Further data, presented in section 2, comprise meteorological data from an automatic weather station (AWS) at Crawford Point (Steffen and others, 1996) and stratigraphic observations at the study site. The isochronous properties of the IRHs are finally used to interpret their distribution in terms of spatial variation of accumulation, and the relation to topography.

\section{DATASETS AND METHODS}

\subsection{Climatological observations}

Meteorological information is available through the Greenland Climate Network (Steffen and others, 1996) from an AWS at Crawford Point, in the vicinity of T05. The station has been in operation since April 1995, and the available record includes hourly mean values of surface air temperature, wind speed and direction as well as snow temperatures (Steffen and Box, 2001). We extract mean surface air temperatures for the three warmest months: June, July and August (JJA). In addition, we calculate a modified positive degree-day factor for each year. This factor is the sum of daily mean temperatures above $0^{\circ} \mathrm{C}$ during a particular period, typically a year (Braithwaite, 1995). Daily mean temperatures generally do not exceed the melting point at this location, as warm air masses are effectively cooled over the ice surface. The factor used here is based on positive hourly mean temperatures and referred to as the positive degree-hour (PDH) factor to distinguish it from the classical positive degree-day factor. In order to yield comparable dimensions, hourly mean values are weighted by a factor of $1 / 24$. Artefacts caused by insufficient ventilation of the temperature sensor are avoided by taking wind speeds above $1 \mathrm{~m} \mathrm{~s}^{-1}$ as a constraint for the 
inclusion of temperatures. The PDH factor is only minimally altered by this constraint.

To determine the onset of melt we use the day of year (DOY) at which two threshold values of PDH factors are reached: $\mathrm{DOY}_{0.1}$ (PDH factor $=0.1$ ) indicates the DOY when the first short events with above-zero temperatures occur; DOY $_{1.0}(\mathrm{PDH}$ factor $=1.0)$ provides the DOY at which a stage of more persistent positive temperatures is present, likely causing some surface melt. For the time period between these days, the mean-snow temperature has been calculated using the record of a thermistor deployed at an initial depth of $1.1 \mathrm{~m}$ below the surface. This set of parameters describes the magnitude of meltwater generated at the surface as well as the cold content of the snow at the onset of melt. It gives a qualitative picture of the conditions to determine meltwater percolation and refreezing during a particular summer season. A detailed analysis of the AWS data is beyond the scope of the present study.

Data analysis indicates warm summers in 1995, 1999, 2002, 2003 and 2004 (Table 1). The years 1995, 1998, 2002 and 2003 were reported earlier as years of extreme melt throughout large parts of the Arctic, both in terms of the aerial extent and total amount of melt (ACIA, 2004; Steffen and others, 2004). Enhanced summer melting during these years covers the western slope of the Greenland ice sheet. The PDH factors from 1995 to 2004 range from 0.3 to 11.0 . The highest values (>9.0) occurred in 1999, 2002, 2003 and 2004 , a moderate value in 1995 , and small values $(<5.0)$ in the other years. The $\mathrm{DOY}_{0.1}$ is in the range $142-188$, and DOY $_{1.0}$ varies from 152 to 224 . The time period between these two threshold values ranges from 2 to 44 days. In 1996, the year with the coldest summer and lowest PDH factor, the second threshold value was not reached at all. The period between the threshold values is generally longer for cold summers than for warm summers. Snowpack temperatures at the onset of melt range from -15.9 to $-19.0^{\circ} \mathrm{C}$, indicating a large cold content of the snow for all years in the record.

\subsection{Snow-pit and firn-core data}

During spring (19 April-13 May) and late summer 2004 (28 August-21 September), stratigraphic records were retrieved from the survey area from nine snow pits and shallow firn cores. The sites were located at point T05 and at distances of 1, 10, 100 and 1000 m east-northeast and southsoutheast from T05, parallel and perpendicular to the EGIG line. These points are referred to as T05-E1 to E4, and T05-S1 to S4, respectively. Observations and measurements comprise visual snow stratigraphy, a qualitative description of layers and snow density. In spring, the last-summer melt surface (LSS) was reached in snow pits at a mean depth of $1.43 \mathrm{~m}$. The LSS was characterized by a flat and hard ice layer beneath the late-summer depth hoar (Parry and others, 2007). The mean snowpack density $\rho$ of all sites was $420 \mathrm{~kg} \mathrm{~m}^{-3}$. Density variations in the winter layer were small. From the bottom of each pit, a shallow core with an approximate length of $2 \mathrm{~m}$ was drilled. The cores penetrated into a heterogeneous zone of metamorphosed snow, containing ice lenses and discontinuous ice layers below the LSS. At point T05-E3, $100 \mathrm{~m}$ east of T05, a longer core down to $18.9 \mathrm{~m}$ depth below the surface was additionally retrieved.

Repeated measurements in late summer reached the LSS at $1.51 \mathrm{~m}$ depth (5.3\% increase compared to the spring depth) and a mean density of $530 \mathrm{~kg} \mathrm{~m}^{-3}(+26.2 \%$ compared to spring). Consequently, the water equivalent (w.e.) depth of
Table 1. Parameters characterizing onset and amount of meltwater generation at the surface as well as initial conditions affecting percolation into the snowpack, derived from AWS data from Crawford Point (Steffen and others, 1996)

\begin{tabular}{|c|c|c|c|c|c|c|c|}
\hline Year & $\begin{array}{c}T_{\text {air }}(\mathrm{JJA}) \\
{ }^{\circ} \mathrm{C}\end{array}$ & $\begin{array}{l}\mathrm{PDH} \\
{ }^{\circ} \mathrm{C}\end{array}$ & DOY $_{0.1}$ & $\mathrm{DOY}_{1.0}$ & $\begin{array}{c}T_{\text {snow }} \\
{ }^{\circ} \mathrm{C}\end{array}$ & $M_{\mathrm{m}}$ & $T_{\mathrm{i}}$ \\
\hline 2004 & -4.7 & 9.7 & 171 & 173 & -15.9 & + & + \\
\hline 2003 & -5.5 & 11.0 & 174 & 212 & -17.3 & + & o \\
\hline 2002 & -5.9 & 10.5 & 161 & 163 & -19.0 & + & - \\
\hline 2001 & -6.2 & 2.6 & 163 & 189 & -18.0 & - & o \\
\hline 2000 & -6.6 & 4.4 & 188 & 191 & -16.9 & o & o \\
\hline 1999 & -5.6 & 9.7 & 177 & 179 & -16.1 & + & + \\
\hline 1998 & -5.2 & 2.9 & 142 & 152 & -18.5 & o & - \\
\hline 1997 & -6.6 & 4.1 & 180 & 224 & -19.0 & o & - \\
\hline 1996 & -8.6 & 0.3 & 171 & - & -16.6 & - & o \\
\hline 1995 & -4.9 & 7.0 & 159 & 183 & -16.5 & + & o \\
\hline
\end{tabular}

Notes: $T_{\text {air }}$ : air temperature for June, July and August (JJA); $\mathrm{PDH}$ : positive degree-hour factor; $\mathrm{DOY}_{0.1,1.0}$ : DOY when $\mathrm{PDH}$ reaches threshold value $(0.1,1.0) ; T_{\text {snow }}$ : snow temperature; $M_{m}$ : qualitative magnitude of melt; $T_{\mathrm{i}}$ : initial snow temperature at the onset of melt. $M_{\mathrm{m}}$ and $T_{\mathrm{i}}$ are divided into three qualitative classes: low $(-)$, moderate/undecided (o) and high (+).

the layer accumulated from the previous summer increased from $60.5 \mathrm{~cm}$ in spring to $79.6 \mathrm{~cm}$ in late summer, an increase of $31.6 \%$ (Parry and others, 2007). The density profiles showed more complex variations in late summer than in spring due to the presence of solid ice structures. Ice layers showed little spatial continuity, even at length scales as short as $1 \mathrm{~m}$. An exception was a spatially continuous, $10-15 \mathrm{~cm}$ thick ice layer located at 3-3.5 m depth, potentially related to extreme summer melting in 2002 (Scott and others, 2006). Ice layers were present at all depths of the snow pits, more or less evenly distributed with no preferable depth of higher number density.

\subsection{GPR data acquisition and processing}

The GPR data were collected from 29 April to 11 May 2004 using a commercial radar system (RAMAC, Malå GeoScience) operating with shielded antennae at frequencies of 500 and $800 \mathrm{MHz}$. The GPR profiles form a grid of $100 \mathrm{~m} \times$ $100 \mathrm{~m}$ with $10 \mathrm{~m}$ line spacing and were oriented parallel (west-southwest-east-northeast) and perpendicular (southsoutheast-north-northwest) to the EGIG line. Additional GPR measurements were performed along $1 \mathrm{~km}$ sections forming a square (Fig. 1). A global positioning system (GPS) receiver was operated together with the GPR for simultaneous kinematic positioning. Static GPS measurements were additionally performed at the beginning and end of each profile. Gaps in the GPS data, resulting from the kinematic operation, were filled by linear interpolation between nearest kinematic or static points. A GPS reference station was operated at T05 and used for post-processing differential GPS data.

GPR shots were triggered every $0.1 \mathrm{~m}$ by means of an odometer attached to the sledge, which was pulled by hand. However, some slip caused the actual trace interval to vary between 0.10 and $0.12 \mathrm{~m}$, reducing the number of traces along the profiles by up to $15 \%$. To increase the signalto-noise ratio during data acquisition, eight traces were recorded at each shot point location at a repetition rate of $200 \mathrm{kHz}$ (quasi-instantaneously) and stacked. The receiving 

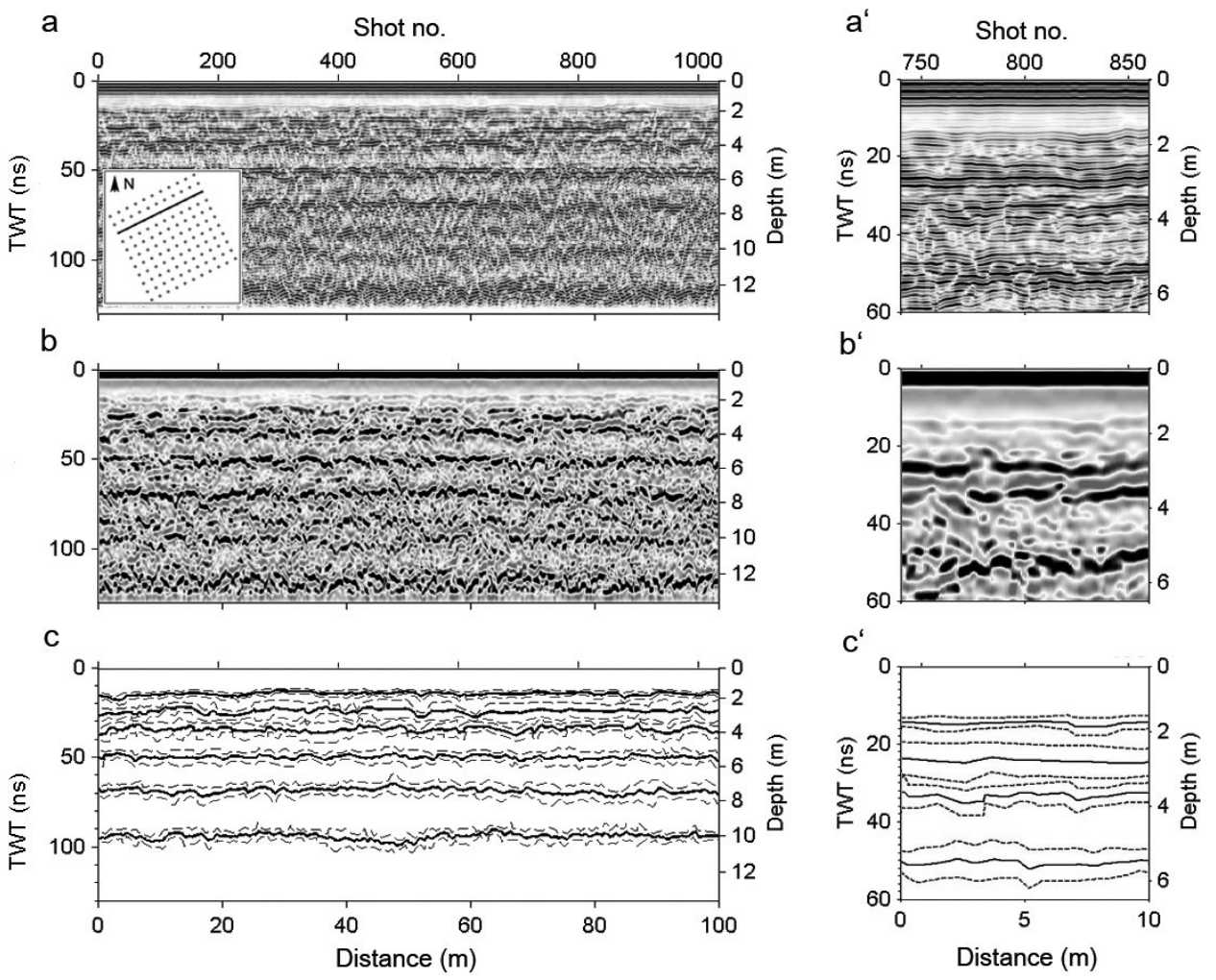

Fig. 2. Sample $500 \mathrm{MHz}$ GPR profile, aligned approximately east-west as indicated in the inset in (a). Panels on the left (a, b, c) cover $100 \mathrm{~m}$; panels on the right $\left(a^{\prime}, b^{\prime}, c^{\prime}\right)$ provide a $10 \mathrm{~m}$ wide close-up. $\left(a, a^{\prime}\right)$ Statically corrected, filtered and gain-corrected radargram, displaying signal amplitude; (b, b') as (a), displaying signal envelope; (c, $\left.\mathrm{c}^{\prime}\right)$ tracked bands of high reflectivity of IRHs (upper and lower edge as dashed lines, computed centre line as solid line).

time window was $130 \mathrm{~ns}$, corresponding to a depth range of about $13.5 \mathrm{~m}$ with 1024 samples and a sample interval of $\sim 0.13 \mathrm{~ns}$. The wavelength $\lambda$ in dry firn $\left(\rho=500 \mathrm{~kg} \mathrm{~m}^{-3}\right)$ is $\sim 0.42 \mathrm{~m}$ and $\sim 0.26 \mathrm{~m}$ for the $500 \mathrm{MHz}$ and $800 \mathrm{MHz}$ antennae, respectively. The GPR system is designed such that the centre frequency corresponds to the bandwidth. The theoretical resolution $(\lambda / 4)$ of the $500 \mathrm{MHz}$ and $800 \mathrm{MHz}$ antennae is therefore about $0.1 \mathrm{~m}$ and $0.06 \mathrm{~m}$, respectively. This is limited by the length of the transmitted wavelets, however, comprising two to three cycles at $500 \mathrm{MHz}$ and three to five cycles at $800 \mathrm{MHz}$, as interferences from partial reflections at inhomogeneities within the length of the wavelets occur.

Radar data were processed using the seismic software Focus/Disco (Paradigm Geophysical). Processing steps included static correction, bandpass filtering, complex trace analysis and gain adjustment (linear gain function and automatic gain control). For the static correction, individual traces were shifted such that the arrival times of the direct waves correspond to the theoretical arrival time in air, determined by the antennae spacing. Semi-automatic tracking routines in the Landmark software package SeisWorks2D (Halliburton) facilitated the tracking of continuous IRHs (Fig. 2a). To ensure that the same horizon was tracked throughout the record, intersections of previously tracked horizons were displayed as markers in the current profile. Cross-point errors in IRH depths from intersecting profiles are thus reduced.

Displaying the amplitude of the received signals, IRHs appear as bands of high reflectivity. Due to the abovementioned length of the transmitter wavelet, the reflection horizons encompass multiple cycles of high amplitude (Fig. 2a). The uppermost 10-15 ns of the radargrams are masked by the arrival of the direct wave and cannot be used for analysis. Likewise, the lowermost $10 \mathrm{~ns}$ are blanked by the gain function.

The bands of high reflectivity become more clearly visible and focused when instead of the signal amplitude the signal envelope is displayed (Fig. 2b). The envelope display emphasizes zones of high reflectivity (strong instantaneous signal magnitude) vs zones of low reflectivity as it omits the zero-amplitude transitions. As the recorded radar data represent the real part of a complex signal, the imaginary part can be reconstructed by the Hilbert transform. Complex trace analysis yields the envelope, also termed the instantaneous magnitude of the complex signal, while the phase information is lost (Mari and others, 1999).

The upper and lower edges of each band were tracked by logging trace number and two-way travel time (TWT) of the sample exceeding a threshold magnitude. The mean TWT of both values determines the centre line of the IRH, which coincides approximately with the maximum signal magnitude (Fig. 2c). The difference in the TWT between the upper and lower edge is referred to as the IRH width.

For later analysis, we converted the recorded radar signals from the time domain to the depth domain. The wave speed $v$ of the radar signal in snow is determined by the permittivity, $v=c / \sqrt{\varepsilon_{r}^{\prime}}$, where $c$ is the speed of light in vacuum. We used the empirical relation of Kovacs and others (1995), $\varepsilon_{\mathrm{r}}^{\prime}=(1+0.000845 \rho)^{2}$, to link density and permittivity $\varepsilon^{\prime}$ where the snow density $\rho$ is in $\mathrm{kg} \mathrm{m}^{-3}$. Finally, the results for reflector depth are half the TWT multiplied by the average wave speed to that depth. A typically observed mean density of $500 \mathrm{~kg} \mathrm{~m}^{-3}$ corresponds to a wave speed 
Table 2. Mean values of two-way travel time, depth and cumulative mass of IRHs and associated IRH width. Variation refers to one standard deviation of the spatial mean. Accumulation values apply to the layer above the IRH, bounded by the upper adjacent IRH

\begin{tabular}{|c|c|c|c|c|c|c|c|}
\hline IRH & $\begin{array}{l}\text { TWT } \\
\text { ns }\end{array}$ & $\begin{array}{l}\text { Depth } \\
\text { m }\end{array}$ & $\begin{array}{l}\text { Cumulative mass } \\
\qquad \mathrm{kg} \mathrm{m}^{-2}\end{array}$ & $\begin{array}{l}\text { IRH width } \\
\text { m }\end{array}$ & $\begin{array}{l}\text { Age } \\
\text { years }\end{array}$ & Possible origin & $\begin{array}{c}\text { Accumulation } \\
\mathrm{kg} \mathrm{m}^{-3} \mathrm{a}^{-1}\end{array}$ \\
\hline IRH-15 & $13.6 \pm 0.9$ & $1.48 \pm 0.10$ & $636 \pm 43$ & $0.49 \pm 0.13$ & $1.4 \pm 0.5$ & LSS 2003 & $636 \pm 43$ \\
\hline IRH-25 & $21.3 \pm 1.2$ & $2.29 \pm 0.17$ & $1012 \pm 82$ & $0.73 \pm 0.21$ & $2.2 \pm 0.8$ & LSS 2002* & $376 \pm 125$ \\
\hline IRH-35 & $32.5 \pm 1.9$ & $3.45 \pm 0.17$ & $1604 \pm 93$ & $0.87 \pm 0.25$ & $3.5 \pm 1.2$ & LSS $2001^{*}$ & $592 \pm 175$ \\
\hline IRH-50 & $49.9 \pm 2.1$ & $5.21 \pm 0.21$ & $2480 \pm 99$ & $0.80 \pm 0.21$ & $5.4 \pm 1.8$ & LSS 1999 & $438 \pm 96$ \\
\hline IRH-70 & $67.9 \pm 2.8$ & $7.04 \pm 0.19$ & $3490 \pm 87$ & $0.83 \pm 0.23$ & $7.6 \pm 2.4$ & LSS 1997 & $505 \pm 93$ \\
\hline IRH-95 & $94.7 \pm 3.3$ & $9.86 \pm 0.17$ & $4960 \pm 99$ & $0.76 \pm 0.22$ & $10.8 \pm 3.4$ & LSS 1994* & $490 \pm 62$ \\
\hline
\end{tabular}

*Ice may have accreted on top of the LSS during the following summer, thereby altering the origin of the IRH.

of $2.1 \times 10^{8} \mathrm{~m} \mathrm{~s}^{-1}$. During data acquisition in spring, the snow was completely frozen (as evident from thermistor data at Crawford Point). Effects of liquid water on the propagation of the radar signal can therefore be safely neglected.

The error in the depth determination of a tracked reflection can be split into range-dependent and range-independent contributions. The former include inaccuracies in the correction of arrival times, assumed to be on average no larger than one sample $(0.13 \mathrm{~ns}$ or $\sim 1.5 \mathrm{~cm})$, and inaccuracies in $\mathrm{IRH}$ tracking. Tracking IRHs is a partly subjective process; quantifying the related error is therefore difficult. We estimate the related error to be five samples $(0.6 \mathrm{~ns}$ or $\sim 6 \mathrm{~cm})$.

Range-dependent errors are introduced in the conversion of TWT to depth, due to deviations from the snow densitydepth model. Because of the depth-averaging of the velocity profile, the conversion from time to depth domain is less prone to errors from variations in density on short vertical length scales at a single location. Rather, it is a deviation of the mean or bulk density along the GPR profiles that introduces depth errors. We analyze density-depth profiles from seven snow pits and firn cores within $100 \mathrm{~m}$ of T05. The standard deviation of bulk densities from one pit to another rapidly decreases with depth and falls below $4 \%$ at $1 \mathrm{~m}$ depth. For simplicity, we assume a maximum error of $4 \%$ in the density-depth model, constant over the whole depth range of the GPR. The related maximum error in TWT-depth conversion increases from $0 \mathrm{~cm}$ at the surface to $>15 \mathrm{~cm}$ at $10 \mathrm{~m}$ depth. The sum of the three error contributions adds up to a maximum error in IRH depth of $\leq 10 \mathrm{~cm}$ in the upper $2 \mathrm{~m}$ to almost $25 \mathrm{~cm}$ in $10 \mathrm{~m}$ depth.

\section{ORIGIN AND INTERPRETATION OF INTERNAL REFLECTION HORIZONS}

Exploiting the distribution of IRHs to derive information about spatio-temporal variations in accumulation requires that the IRHs are isochrones. This implies that an individual IRH obtains its physical properties at the same time and maintains this characteristic while being submerged to a larger depth. The origin of the IRHs is investigated in this section. We first compare GPR results obtained at the two different frequencies, and then interpret the IRHs by comparison with observed snow stratigraphy. Based on these results, an age-depth model is established by employing earlier accumulation estimates from ice-core analysis. We finally discuss reasons for the observation of continuous IRHs in comparison to other studies.

\subsection{Comparison of IRHs observed at $\mathbf{5 0 0}$ and $800 \mathrm{MHz}$}

Altogether, six IRHs down to about $10 \mathrm{~m}$ depth could be clearly identified and tracked at both frequencies, within the grid as well as along the $1 \mathrm{~km}$ sections. These are referred to as IRH-15 to IRH-95, with numbers indicating their approximate depth in nanoseconds of TWT near T05 (Table 2). To validate the measurements, 500 and $800 \mathrm{MHz}$ results were first treated independently and later combined. The data at both frequencies reveal the same number of clearly identifiable IRHs, located at approximately the same depths with respect to the IRH centre line. IRHs obtained at $800 \mathrm{MHz}$ appear on average $4.8 \%$ deeper than in the $500 \mathrm{MHz}$ record. The differences in IRH depths increase with depth and range from $0.00 \mathrm{~m}$ for IRH-15 up to $0.52 \mathrm{~m}$ for IRH-95.

To investigate this further, we quantify the spatial variation in depth of each IRH in terms of its standard deviation (depth$\mathrm{SD}$ ). This property will serve as a first-order approximation of the small-scale spatial variability in snow accumulation. We consider it to be a measure of the representativeness of layer depths derived from individual point measurements within a certain area. Applying it to the comparison of 500 and $800 \mathrm{MHz}$ data, it turns out that the depth-SD is on average $7.0 \%$ smaller for the $800 \mathrm{MHz}$ than for the $500 \mathrm{MHz}$ measurements for corresponding IRHs. No trend with respect to depth is present for the ratios of the depth-SD at both frequencies. Regarding differences in IRH widths, the $800 \mathrm{MHz}$ survey yields slightly larger values: $+6.0 \%$ on average. The observed differences in both IRH depths and widths can be considered small. They are most likely caused by variations in constructive and destructive interference from inhomogeneities because of the different frequencies and wavelets. The small differences indicate that IRHs obtained at 500 and $800 \mathrm{MHz}$ likely arise from the same cluster of physical subsurface features.

Unless explicitly stated otherwise, we use mean values of both 500 and $800 \mathrm{MHz}$ measurements for the discussion and interpretation in the rest of this paper. We will focus on the upper edges of IRHs, as they were the easiest to identify, usually occurring below a zone of low reflectivity and thus providing high tracking accuracy. The physical explanation for this observation is discussed in section 3.2.

\subsection{Relation of GPR reflectivity to snow stratigraphy}

Changes in density dominate the reflectivity of the firn pack, while changes in conductivity can be neglected. We now investigate which density features could cause the observed 
IRHs. The upper edge of IRH-15 is located at $1.48 \pm 0.10 \mathrm{~m}$. It corresponds well with the depth of the LSS (end of 2003 summer surface) of $1.43 \pm 0.04 \mathrm{~m}$ (Parry and others, 2007). We therefore consider it likely that IRH-15 arises from strong density contrast at the LSS formed during summer 2003. The IRH width and associated variability of IRH-15 is significantly smaller than for the deeper IRHs. We explain this with the time of data acquisition. As the data were acquired prior to melting conditions in summer, the overlying snowpack has not yet experienced metamorphosis through meltwater intrusion from above. The significantly larger reflector widths of deeper IRHs suggest that these may be influenced or even arise from ice-layer clusters formed during multiple summer seasons.

The depth range below IRH-15, down to approximately $4 \mathrm{~m}$, is characterized by very complex and strong reflections. Two IRHs have been tracked in this depth range. The upper is IRH-25, at and below 2.29 m depth at T05. IRH-25 is laterally discontinuous and partly splits into two separate IRHs. IRH35 , at and below $3.45 \mathrm{~m}$ depth, is laterally well confined towards larger depths, where only weak signal returns are possible.

The AWS data at Crawford Point and the stratigraphic observations at TO5 in late summer 2004 provide an archetype for the development of the snowpack in warm summers, useful for interpreting deeper reflection patterns. The conditions during the melt period 2004 resemble those in the wet snow zone rather than the percolation zone. This is the year (2004) for which the AWS record yields the warmest summer months (June-August) with a mean temperature of $-4.7^{\circ} \mathrm{C}$, a high $\mathrm{PDH}$ factor and the highest initial snowpack temperature at the onset of melt $\left(-15.9^{\circ} \mathrm{C}\right)$. Accordingly, after the melt season, discontinuous ice layers were found at all depths of the snow pits (Parry and others, 2007).

Similar conditions can also be expected for the years 2003 and 2002, for which the AWS data show clearly aboveaverage summer temperatures. An example is the 0.10 $0.15 \mathrm{~m}$ thick ice layer at 3-3.5 m depth (Scott and others, 2006; Parry and others, 2007), which is probably related to the extreme summer melt in 2002. Strong percolation of surface-generated meltwater in 2002 eventually accreted as ice on top of the underlying summer surface. We therefore suggest that IRH-35 partly arises from ice which probably formed during summer 2002 on top of LSS 2001. The complex appearance of IRH-25 above IRH-35 may be a consequence of extensive downward meltwater flow and soaking of the previous accumulation layer during summers 2003 and 2002. IRH-25 could therefore represent both the 2002 summer surface and lower clusters of solid ice structures as well as the ice accreted on top during the following summer.

The 4-5.5 m depth range shows weak signal returns in the GPR data compared to the depth range above. The AWS data for the years 2000 and 2001 show significantly colder summer temperatures expressed in low PDH values as well as colder initial snow temperatures. The winter accumulation during this time period is expected to be less affected by meltwater infiltration and refreezing. To date, an independent age-depth model is not available to confirm these interpretations. However, we can utilize earlier estimates of accumulation to determine a tentative age-depth model.

\subsection{Continuous IRHs}

The detection of continuous IRHs is encouraging for deriving accumulation characteristics. Interestingly, other studies did not observe continuous IRHs. Scott and others (2006) performed measurements at the same site in late summer 2004. Their data, collected along profiles of length $100 \mathrm{~m}$, did not reveal continuous near-surface IRHs.

Three factors are likely to cause this discrepancy. First, they used a ground-based step-frequency radar with a centre frequency of $\sim 13 \mathrm{GHz}$, one set-up with a bandwidth $1 \mathrm{GHz}$, and in a second operational mode with a bandwidth of $8 \mathrm{GHz}$. The higher resolution of their system, compared to that used in the present study, causes higher volume backscatter and a reduced penetration depth. Laterally coherent reflections from layers or similarly layered sequences are therefore less likely to be observed. Second, the trace interval of $0.5 \mathrm{~m}$ up to almost $1.5 \mathrm{~m}$ chosen by Scott and others (2006) is very large with respect to the high antennae resolution. It is therefore possible that despite a small antenna footprint, laterally consecutive first Fresnel zones did not overlap, therefore disabling laterally coherent reflections. In comparison, we used a trace interval of $0.1 \mathrm{~m}$ combined with a significantly lower resolution. Future experiments in comparable areas should take this into account. Finally, the complexity of the radar returns is further enhanced by the change in physical snow properties in the transition from pre- to late-summer conditions.

\subsection{Age-depth model}

Cumulative mass within a depth section divided by the corresponding time of accumulation yields the accumulation rate. We can therefore estimate the age of the IRHs by dividing the ice-core-derived cumulative mass above a particular horizon, obtained by integrating the density down to this horizon, by an independently determined mean accumulation rate at the site (available from earlier studies). We focus on the upper edges of IRHs, interpreted to represent LSSs for which the overlying winter layer is relatively undisturbed by ice accreted on top of the LSS.

Fischer and others (1995) derived accumulation rates along the EGIG line based on isotopic and chemical analysis of shallow firn cores, drilled in 1992. They found the annual mean snow accumulation over an 8 year period at T05 to be $46.0 \pm 10.2 \mathrm{~cm}$ w.e. We attribute the variation of $22 \%$ to interannual variability of accumulation. Guided by the hypothetical time-span of accumulation, we appoint age estimates to the upper edges of IRHs (Table 2). This yields mean accumulation rates of $37.6-63.6 \mathrm{~cm}$ w.e. for periods enclosed by adjacent horizons. The mean accumulation rate over the period 1994-2004 is found to be $49.6 \mathrm{~cm}$ w.e. We estimate a temporal variability of $9.6 \mathrm{~cm}$ w.e. by the standard deviation of the six values, corresponding to the six IRHs. This value has to be considered as a lower limit for the interannual variability, as three of the periods average over 2 and 3 years, respectively. The relative uncertainty in the time since accumulation, and consequently the age estimate, amounts to roughly $30 \%$. The absolute uncertainties therefore increase significantly with depth.

\subsection{Scenarios for IRH formation}

The stratigraphy in the percolation zone is very complex and its interpretation is based more on similar layered sequences than on the identification of specific layers (Benson, 1962). The initial processes for formation of a lateral continuous IRH occur at the snow surface mainly during the summer season. For the subsurface processes, which finally lead to amplification of the initial characteristics to produce 
strong IRHs in the upper $\sim 10 \mathrm{~m}$, we propose the following scenarios.

In general, the IRHs are based on the integral effect of solid ice clusters on GPR signals at 500 and $800 \mathrm{MHz}$, as individual lateral continuous ice layers may be absent. Occasional melt-refreeze cycles during summers with little to moderate surface melt form an ice crust at the surface. Some meltwater infiltrates the snowpack and refreezes in the upper fraction of the layer of the previous winter's accumulation, immediately below the summer surface. Once this layer is submerged and overlain by new accumulation, these features probably appear in the GPR record as a continuous IRH with a defined upper boundary and a rather diffuse lower boundary consisting of isolated signals of high reflectivity. Extensive breakthrough of percolating meltwater during warm summers with severe surface melt produces isolated ice lenses throughout the snowpack, but percolating meltwater may accrete as thick ice on top of the LSS.

This was the case in late summer 2004 where accretion of ice was observed at the bottom of a snow pit at T04 on the EGIG line, at an elevation of $1860 \mathrm{~m}$, just $80 \mathrm{~m}$ lower than T05 (Scott and others, 2006). Because of the strong density contrast between the porous snow matrix and the solid ice layer, this constitutes an inhomogeneity of high reflectivity in the GPR record. However, due to its proximity to the underlying LSS, this feature is barely separable from the LSS below. In case of persistent warm temperatures, extreme surface melt and subsequent meltwater percolation could cause a wetting front to propagate from the surface downwards. This may lead temporarily to snowpack conditions similar to those in the wet-snow zone at lower elevations. It can then form a unit of uniform wetting in an upper fraction of the snowpack, containing a complex mixture of small but numerous ice structures surrounded by coarse-grained snow crystals. As the complete layer thickness down to the underlying LSS is affected, this unit likely appears in the GPR record as a band of high backscatter with no defined lower boundary. Therefore, the continuous reflection from the LSS may be lost as a result of high clutter.

If no melting takes place during the summer, the conditions in the uppermost snow layer resemble those of the dry snow zone. The density, and thus the dielectric contrast, of layers originating from different accumulation events is small compared to normal percolation conditions. Only the formation of distinct layers of hoar or wind crust could provide a large enough density contrast to produce continuous IRHs. However, if this is not the case, then no continuous IRH might be observed with GPR, making it difficult to separate accumulation from subsequent years.

\subsection{Spatio-temporal variation of accumulation}

Here we discuss the spatial distribution of IRHs and the underlying accumulation pattern on different spatial scales. The results are first discussed independently of an age-depth scale in terms of depth and cumulative mass. We then apply the age-depth model established above to discuss the variation of accumulation in the larger regional context.

Over the area of the $100 \mathrm{~m} \times 100 \mathrm{~m}$ grid, IRHs appear as interfaces aligned parallel to the reference surface (Fig. 2). The depth distribution of each IRH is basically of Gaussian shape. The depth-SD of the IRHs varies from 0.10 to $0.21 \mathrm{~m}$, with a mean of $0.17 \mathrm{~m}$, with the smallest value for the uppermost IRH-15, but shows no further systematic trend with depth (Table 2). As all depth-SD values are of the same

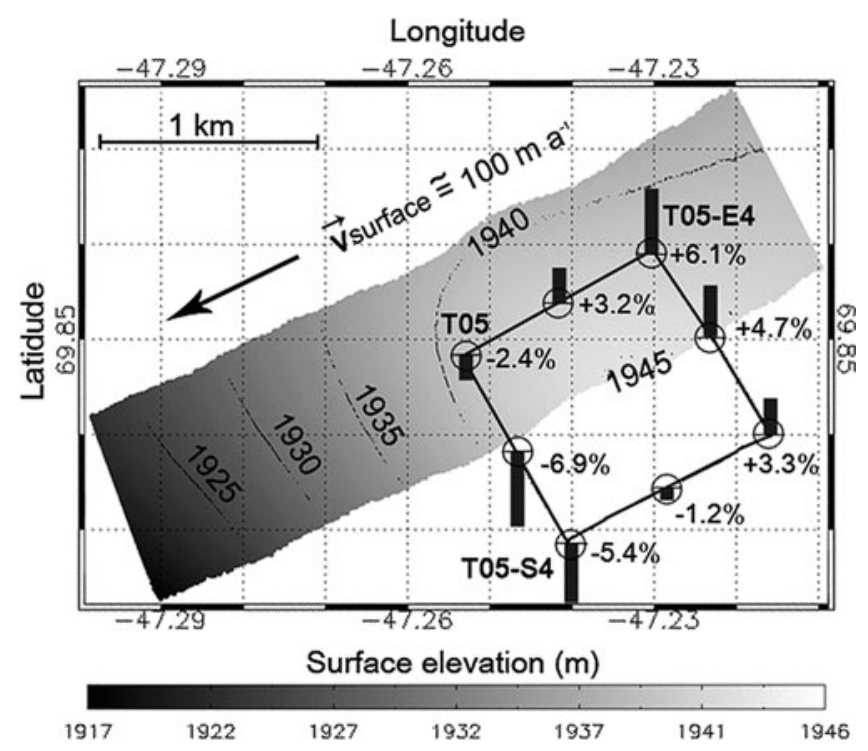

Fig. 3. Digital elevation model with $5 \mathrm{~m}$ contour lines, based on laser scanning during the ASIRAS campaign (Helm and others, 2007). Also shown is the location of the $1 \mathrm{~km} \times 1 \mathrm{~km}$ square and the variation of cumulative mass above IRH-50 along its profiles. Bars visualize percentage deviations of inverse-distance weighted cumulative mass within a search radius of $100 \mathrm{~m}$ with respect to overall mean.

order of magnitude for all horizons, we assume that a consistent spatial gradient in snow accumulation cannot be detected at scales of $100 \mathrm{~m}$ at this location. For this length scale we can therefore estimate the accumulation variation to be $8.5 \mathrm{~cm}$ w.e., derived by multiplying the mean depth-SD with a typical density of $500 \mathrm{~kg} \mathrm{~m}^{-3}$.

To identify a possible spatial gradient in snow accumulation over the area enclosed by the $1 \mathrm{~km} \times 1 \mathrm{~km}$ square, we investigate the distribution of IRH-50. This IRH produces strong and relatively undisturbed return signals, providing reliable results. We compute inverse-distance weighted mean values of cumulative mass for measurements within a search radius of $100 \mathrm{~m}$ from mid-and end-points of the $1 \mathrm{~km}$ sections. Deviations are expressed as percentages of the average mass along all $1 \mathrm{~km}$ sections, indicated as bars in Figure 3. The analysis reveals increasing accumulation towards the northeast, a trend not recognized over the area of the $100 \mathrm{~m} \times 100 \mathrm{~m}$ grid. Values range from $-6.9 \%$ at the mid-point of the line connecting point T05 and point T05-S4 in the southwest to $+6.1 \%$ at point T05-E4 in the northeast. IRHs along the $1 \mathrm{~km}$ sections show an increasing depth-SD with depth, varying between $0.11 \mathrm{~m}$ for $\mathrm{IRH}-15$ and $0.34 \mathrm{~m}$ for IRH-95, with an overall mean of $0.22 \mathrm{~m}$.

Spatial gradients in accumulation of such magnitude have been observed in many areas on ice sheets. They usually represent local effects caused by topographic undulations on small scales (few kilometres) that affect wind-driven redistribution of snow (King and others, 2004). To investigate if this process is also of relevance here, we use the new digital elevation model of the survey area, acquired during the ASIRAS campaign in spring 2004 by laser scanning (Helm and others, 2007).

The topography data indicate that our survey area lies on a plateau, with a nearby slope break to the southwest (Fig. 3). ASIRAS detected a slope-dependent, bimodal distribution of the uppermost-layer snow thickness along a $2.7 \mathrm{~km}$ crossover flight of T05 (Helm and others, 2007). A layer thickness of 

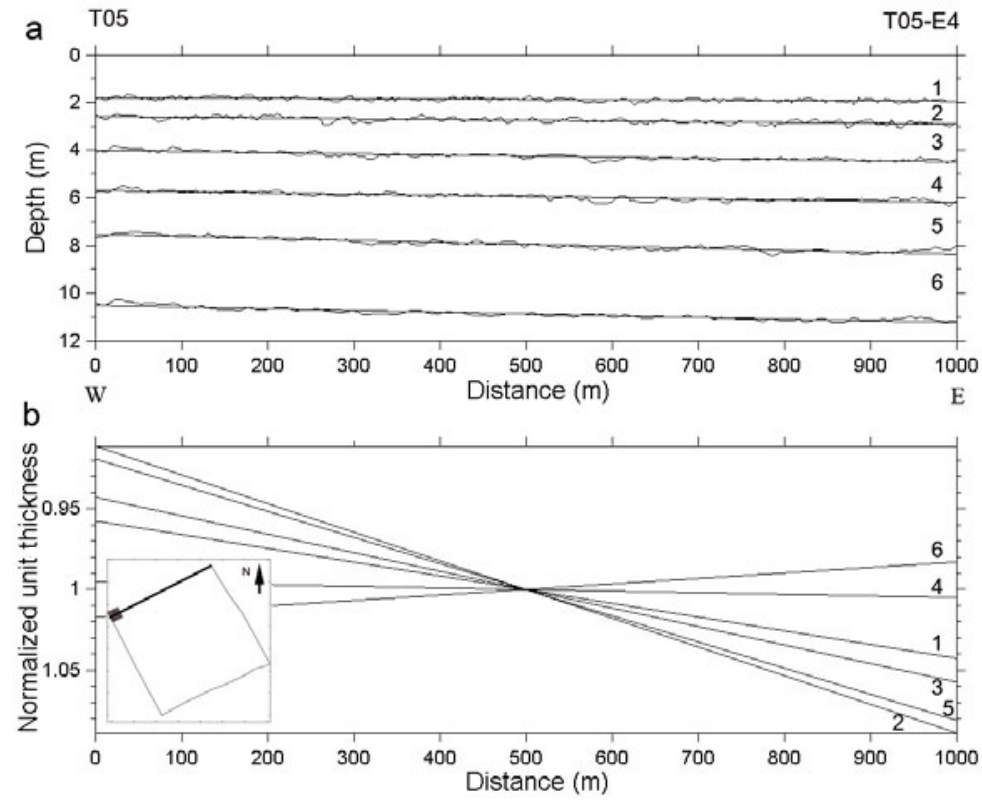

Fig. 4. (a) IRHs along the $1 \mathrm{~km}$ profile east of T05 (see inset in (b)). The positions of IRH centre lines and corresponding linear regression lines are plotted. (b) Normalized thickness for layers enclosed by adjacent horizons, with profile centres crossing the mean (normalized unit thickness $\equiv 1$ ).

$1.30 \pm 0.05 \mathrm{~m}$ was found on the slope (eastwards-rising elevation of $1920-1940 \mathrm{~m})$, and $1.50 \pm 0.13 \mathrm{~m}$ on the plateau (elevations of 1940-1945 m). Our 1 km GPR profiles are situated on the plateau, close to the edge of the area covered by ASIRAS, and obviously fall in a transition zone between the two accumulation modes. The ASIRAS-based layer thickness for the plateau corresponds very well with the depth of IRH15 and the depth of the LSS from snow-pit analysis. While the strong response of the LSS causes complete power loss of the ASIRAS signal for the depth range below, we showed above that the GPR system is capable of detecting continuous IRHs down to $10 \mathrm{~m}$ depth. This enables us to investigate the spatial variability for earlier time periods.

To this end we use selected $800 \mathrm{MHz}$ sections oriented parallel and perpendicular to the EGIG line. IRHs appear to be parallel to the surface along the section perpendicular to the EGIG line. The section following the EGIG line from T05 in a direction east-northeast reveals that IRHs are clearly dipping in that direction (Fig. 4a). To analyze the temporal variability of the spatial gradient in snow accumulation, we determine the thicknesses of units enclosed by adjacent horizons (see unit numbering in Fig. 4). The units were normalized by their corresponding mean thickness. We then performed a linear regression for all units. The fitted lines pass through the centroid ( $x$ mean, $y$ mean; Fig. $4 b$ ). It is evident that the trends along this GPR profile are well represented by linear ap-proximations, indicating that the underlying gradient in snow accumulation is also linear. In general, the gradient appears less strong for deeper and older units than for younger units. The positive gradient in accumulation towards the east-northeast persists for most of the accumulation periods covered by our data.

Layer thicknesses increase by about $10 \%$ from southwest to northeast for units 1,2, 3 and 5 . The trend is reversed for the deepest unit 6 , for which normalized thickness is about $3 \%$ greater at the northeast than at the southwest end. The thickness of unit 4 is almost constant. The observed weakening of the gradient with depth could be explained by the fact that we neglect ice advection. The surface velocity of the ice flow at the survey site is about $100 \mathrm{~m} \mathrm{a}^{-1}$. Ten-year-old firn originates about $1 \mathrm{~km}$ upstream from the present location, further up on the plateau, where ASIRAS detected little variability in snow accumulation (Helm and others, 2007).

The age estimate of the six IRHs enables us to convert the observed IRH depths and cumulative mass discussed above to accumulation values. The previous year's accumulation (summer 2003-spring 2004) yields $63.6 \pm 4.3 \mathrm{~cm}$ w.e. This value is about $40 \%$ larger than previously derived accumulation rates (Fischer and others, 1995), but is in agreement with the snow-pit derived accumulation of $60.5 \pm 3.4 \mathrm{~cm}$ w.e. (Parry and others, 2007). It should be noted that this is a preliminary lower-limit result, since the mass-balance year was not fully completed by the time of data acquisition. The observed northeast gradient in snow accumulation is of the order $5.0 \mathrm{~cm}$ w.e. $\mathrm{km}^{-1}$, roughly $10 \%$ of the mean per $\mathrm{km}$. This value is one order of magnitude larger than the regional trend on a $100 \mathrm{~km}$ scale on existing maps of accumulation rates over Greenland (Bales and others, 2001). We explain this discrepancy as the result of the difference between local and regional elevation trends influencing the katabatic wind speed and thus post-depositional redistribution of snow. Whereas the regional slope inland of the study site is of the order $1-5 \times 10^{-3}$ (i.e. $100-500 \mathrm{~m}$ over $100 \mathrm{~km}$; Fig. 1), local slopes in the plateau-like area of the $1 \mathrm{~km}$ square amount to $\sim 10^{-2}$ (Fig. 3). The ASIRAS observation of further decreasing accumulation on the larger slope in the west confirms this relation.

The redistribution of mass by percolation in years of strong melt could cause a higher uncertainty for the estimated accumulation values. Percolating meltwater during summer 2003 could have caused ice accretion on top of the LSS of 2002 (IRH-25). This mass would therefore contribute to the value computed for the previous period 2001/02, but would be lacking in the period 2002/03. Thus, the minimum accumulation rate of $37.6 \pm 12.5 \mathrm{~cm}$ w.e. for the period 2002/03 (Table 2) is likely an underestimate of the full balance year. 
Mass loss by percolation may also apply for the the period $2001 / 02$. If the amount of loss by percolation and gain by internal accumulation were comparable in both periods, the downward loss of mass and the gain from above would be compensated.

\section{CONCLUSIONS}

We analyzed GPR measurements at one particular location in the percolation zone of Greenland using frequencies of 500 and $800 \mathrm{MHz}$ on scales of up to $1 \mathrm{~km}$. The characteristics of the GPR record in the upper 5-6 $\mathrm{m}$ depth were related to meteorological conditions during previous melt seasons. The GPR-derived depth of the LSS (2003) around 1.4-1.5 m is in very good agreement with the depth as observed both in snow pits and by ASIRAS. The very complex radar response at $1.5-4.0 \mathrm{~m}$ depth is probably related to severe percolation and subsequent refreezing of large amounts of surface-generated meltwater during the extreme summers of 2003 and 2002. Reflections in the depth range $4.0-5.5 \mathrm{~m}$ are of significantly lower energy and less complex. They likely coincide with cold to moderate summer conditions in 2000 and 2001.

Relating the GPR record to snow stratigraphy, we conclude that the continuous IRHs are basically isochrones in the sense that each was generated during one melting season. Not only can they arise from specific ice layers, but also from clusters of solid ice structures in vertically bounded sequences. The structure of the IRH seems to depend upon initial snowpack conditions at the onset of melt and summer temperatures in the melt season that generated the IRH. Features leading to coherent and laterally continuous horizons can encompass isolated typical ice layers in the upper part of the snowpack, small but numerous ice clusters in a layer that was previously wetted considerably and accretion of ice or highly compacted firn at the bottom of an annual accumulation layer.

In the case of extreme melting, the characteristics of deeper IRHs may be altered by strong meltwater percolation. As a consequence, IRHs may not be clearly identifiable every year. The choice of wavelengths of the order several decimetres and high spatial sampling are a prerequisite for detecting continuous IRHs. At higher frequencies in the Ku-band, stronger volume backscatter, less distinct integral effects of ice-layer clusters on the radar return, and significantly lower signal penetration, may inhibit detection of laterally continuous sequences.

The distribution of the IRHs over the area of investigation is related to accumulation. For an area of approximately $100 \mathrm{~m} \times 100 \mathrm{~m}$ around T05, accumulation values derived from individual snow pits or firn cores have uncertainties of about $8.5 \mathrm{~cm}$ w.e. or $15 \%$ of the mean accumulation, as determined through depth-SD analysis of the GPR survey. Over a distance of $1 \mathrm{~km}$, an additional local trend in accumulation of $5.0 \mathrm{~cm}$ w.e. $\mathrm{km}^{-1}$ is present parallel to the EGIG line. This trend is about 10 times larger than the regional gradient. The variation in accumulation is likely related to topographic undulations, which affect wind-driven redistribution of snow. An observed weakening of the gradient for accumulation derived from deeper IRHs may be due to the fact that deeper units originate further upstream where surface slopes are comparably small, and accumulation is thus more uniform.

Compared with currently applicable airborne radar altimeters such as ASIRAS, or upcoming satellite sensors such as CryoSat's Synthetic Aperture Radar Interferometric Radar Altimeter (SIRAL), GPR systems naturally achieve a much lower spatial coverage. However, especially in the percolation zone, GPR has the advantage that deeper, older IRHs can be detected, allowing investigations not only of spatial but also temporal variability of accumulation. As full utilization of either dataset requires independent age-depth models, regular snow-pit and firn-core studies will remain necessary in operational stages of remote-sensing missions.

\section{ACKNOWLEDGEMENTS}

CryoVEx 2004 was funded by the European Space Agency (C18677/04/NL/GS) and supported by the German Aerospace Research Center (DLR) (50EE0505). O. Eisen was supported through an 'Emmy Noether' scholarship El 672/1 of the Deutsche Forschungsgemeinschaft. We gratefully acknowledge the Greenland Climate Network for providing the AWS record from Crawford Point. Thanks to P. Nienow and D. Mair for collection of the snow stratigraphy records in the field and to T. V. Schuler for inspiring discussions of the AWS record. We also thank T. Scambos and two anonymous reviewers for critical remarks on the manuscript.

\section{REFERENCES}

Arctic Climate Impact Assessment (ACIA). 2004. Impacts of a warming Arctic: Arctic Climate Impact Assessment. Cambridge, etc., Cambridge University Press.

Bales, R.C., J.R. McConnell, E. Mosley-Thompson and G.W. Lamorey. 2001. Accumulation map for the Greenland ice sheet: 1971-1990. Geophys. Res. Lett., 28(15), 2967-2970.

Benson, C.S. 1962. Stratigraphic studies in the snow and firn of the Greenland ice sheet. SIPRE Res. Rep. 70.

Braithwaite, R.J. 1995. Positive degree-day factors for ablation on the Greenland ice sheet studied by energy-balance modelling. J. Glaciol., 41(137), 153-160.

Fettweis, X., J.P. van Ypersele, H. Gallée, F. Lefebre and W. Lefebvre. 2007. The 1979-2005 Greenland ice sheet melt extent from passive microwave data using an improved version of the melt retrieval XPGR algorithm. Geophys. Res. Lett., 34(5), L05502. (10.1029/2006GL028787.)

Fischer, H., D. Wagenbach, M. Laternser and W. Haeberli. 1995. Glacio-meteorological and isotopic studies along the EGIG line, central Greenland. J. Glaciol., 41(139), 515-527.

Helm, V. and 6 others. 2007. Winter accumulation in the percolation zone of Greenland measured by airborne radar altimeter. Geophys. Res. Lett., 34(6), L06501. (10.1029/2006GL029185.)

Hofmann, W. 1986. Bewegung des Inlandeises im West-Ost-Profil von 1959 bis 1967. In Die deutschen geodätischen Arbeiten in Rahmen der Internationalen glaziologischen Grönland Expedition (EGIG) 1959-1974. München, Bayerische Akademie der Wissenschaften. Deutsche Geodätische Kommission, 43-61.

Jezek, K.C., P. Gogineni and M. Shanableh. 1994. Radar measurements of melt zones on the Greenland ice sheet. Geophys. Res. Lett., 21(1), 33-36.

Kanagaratnam, P., S.P. Gogineni, V. Ramasami and D. Braaten. 2007. A wideband radar for high-resolution mapping of nearsurface internal layers in glacial ice. IEEE Trans. Geosci. Remote Sens., 42(3), 483-490.

King, J.C., P.S. Anderson, D.G. Vaughan, G.W. Mann, S.D. Mobbs and S.B. Vosper. 2004. Wind-borne redistribution of snow across an Antarctic ice rise. J. Geophys. Res., 109(D11), D11104. (10.1029/2003JD004361.)

Kovacs, A., A.J. Gow and R.M. Morey. 1995. The in-situ dielectric constant of polar firn revisited. Cold Reg. Sci. Technol., 23(3), 245-256.

Krabill, W. and 9 others. 2000. Greenland Ice Sheet: high-elevation balance and peripheral thinning. Science, 289(5478), 428-430. 
Male, D.H. 1980. The seasonal snowcover. In Colbeck, S.C., ed. Dynamics of snow and ice masses. New York, Academic Press, 305-395.

Mari, J.L., F. Glangeaud and F. Coppens. 1999. Signal processing for geologists and geophysicists. Paris, Éditions Technip.

Parry, V. and 6 others. 2007. Investigations of meltwater refreezing and density variations in the snowpack and firn within the percolation zone of the Greenland Ice Sheet. Ann. Glaciol., 46, 61-68.

Pfeffer, W.T. and N.F. Humphrey. 1996. Determination of timing and location of water movement and ice-layer formation by temperature measurements in sub-freezing snow. J. Glaciol., 42(141), 292-304.

Pfeffer, W.T. and N.F. Humphrey. 1998. Formation of ice layers by infiltration and refreezing of meltwater. Ann. Glaciol., 26, 83-91.

Scott, J., D. Mair, P. Nienow, V. Parry and E. Morris. 2006. A ground-based radar backscatter investigation in the percolation zone of the Greenland Ice Sheet. Remote Sens. Environ., 104(4), 361-373.
Shepherd, A. and D. Wingham. 2007. Recent sea-level contributions of the Antarctic and Greenland ice sheets. Science, 315(5818), 1529-1532.

Steffen, K. and J. Box. 2001. Surface climatology of the Greenland ice sheet: Greenland Climate Network 1995-1999. J. Geophys. Res., 106(D24), 33,951-33,964.

Steffen, K., J. Box and W. Abdalati. 1996. Greenland climate network: GC-Net. CRREL Spec. Rep. 96-27, 98-103.

Steffen, K., S. Nghiem, R. Huff and G. Neumann. 2004. The melt anomaly of 2002 on the Greenland Ice Sheet from active and passive microwave satellite observations. Geophys. Res. Lett., 31(20), L20402. (10.1029/2004GL020444.)

Zabel, I.H.H., K.C. Jezek, P.A. Baggeroer and S.P. Gogineni. 1995. Ground-based radar observations of snow stratigraphy and melt processes in the percolation facies of the Greenland ice sheet. Ann. Glaciol., 21, 40-44.

Zwally, H.J. and 7 others. 2005. Mass changes of the Greenland and Antarctic ice sheets and shelves and contributions to sea-level rise: 1992-2002. J. Glaciol., 51(175), 509-527. 